\title{
A Practical Approach to Emergencies in the Neonatal Period
}

Alonso Mata-Peréz ${ }^{1}$, Manuel Soto-Martínez ${ }^{2}$ and Adriana Yock-Corrales ${ }^{1^{*}}$

${ }^{1}$ Emergency Department, Hospital Nacional de Niños "Dr. Carlos Saenz Herrera”, San José, Costa Rica ${ }^{2}$ Respiratory Department, Hospital Nacional de Niños “Dr. Carlos Sáenz Herrera”, San José, Costa Rica

"Corresponding author: Adriana Yock-Corrales, Servicio de Emergencias Pediátricas, Hospital Nacional de Niños “Dr. Carlos Sáenz Herrera”, Avenida Paseo Colón, San José, Costa Rica, Tel: (506) 8390-0516; E-mail address: adriyock@gmail.com

Received date: January 26, 2016; Accepted date: February 17, 2016; Published date: February 25, 2016

Copyright: (c) 2016 Peréz AM, et al. This is an open-access article distributed under the terms of the Creative Commons Attribution License, which permits unrestricted use, distribution, and reproduction in any medium, provided the original author and source are credited.

\begin{abstract}
All emergency departments should be prepared to care for a critically ill infant, including having the appropriate sized equipment. The most common diagnosis in admitted neonates include respiratory infections, sepsis, congenital heart disease, bowel obstruction, hypoglycemia and seizures. Febrile neonates are at high risk for sepsis and therefore need blood, urine and CSF testing. These patients should receive empiric antibiotic therapy in hospital. There are many life-threatening illness that can affect this population and is the responsibility of the emergency physician to assess the neonate, stabilize, narrow the differential diagnosis to the most likely and begin life-sustaining treatment. Very different types of illnesses can affect a child in the neonatal period and some can give us different clinical presentation. For example, the spectrum of congenital heart disease presenting in the newborn period and early infancy ranges from benign to catastrophic. Neonatal seizures may have subtle manifestations and require a different approach than seizures in older infants and children. This is a review of the more common but life threatening pathologic conditions in the neonate if not managed adequately.
\end{abstract}

Keywords: Neonates; Abdomen; Neonatal seizures; Infant

\section{Introduction}

Management of a critically ill neonate in the emergency department (ED) is challenging. The evaluation and appropriate management of the ill neonate requires a deep knowledge of the physiologic changes and life-threating pathologic conditions that may present during this time. Most visits to an ED will be because of nonserious diseases, mainly because of insufficient caretaker information [1]. Young neonates (less 10 days old) who present to the ED have a particularly high incidence of serious illness, with $10 \%$ to $33 \%$ requiring hospital admission. A broad systematic approach is necessary, to provide a comprehensive and specific assessment for the presenting symptom. The early diagnosis and management may be life saving. The new change policies in the early discharge of the neonates from the newborn nurseries ensure the necessity of the emergency physician to know the numerous clinical situations $[2,3]$.

\section{Recognition of the critically ill neonate}

The history and the physical examination are essential in how the clinician will approach the patient, and make the appropriate diagnostic test for a correct diagnosis. A complete history may unmask the likely cause of symptoms and guide the further questioning. Prenatal and perinatal history will guide the physician to certain entities. For example, prolonged membrane rupture or perinatal maternal fever gives an important risk factor for sepsis. Prematurity is significant risk factor for necrotizing enterocolitis and late onset sepsis.

In assessing the symptoms of an ill infant, the emergency clinician should be familiar with the spectrum of activities expected in a healthy neonate; also knowing anatomic and physiologic changes that occur in the first month of life is critical to understanding the pathophysiology of many neonatal disorders.

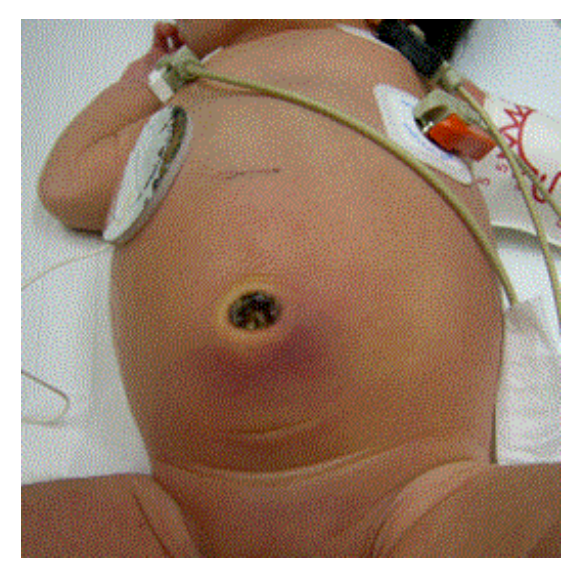

Figure 1: A neonate with an omphalitis.

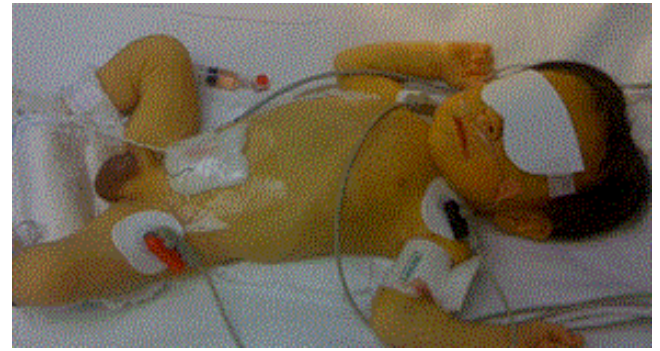

Figure 2: A neonate with hyperbilirubinemia. 
Page 2 of 9

\begin{tabular}{|l|l|}
\hline \multicolumn{2}{|l|}{ Clinical Presentation } \\
\hline Temperature & Hyperthermia (more common in full term infant) \\
\hline Irregularity & Hypothermia (more common than fever in Preterm) \\
\hline Change in Behavior & Lethargy, irritability or moaning \\
\hline Skin & $\begin{array}{l}\text { Poor peripheral perfusion, cyanosis, pallor, petechial, } \\
\text { rashes }\end{array}$ \\
\hline $\begin{array}{l}\text { Gastrointestinal } \\
\text { problems }\end{array}$ & $\begin{array}{l}\text { Feeding intolerance, vomiting, diarrhea, or abdominal } \\
\text { distention with or without visible bowel loops }\end{array}$ \\
\hline Cardiopulmonary & $\begin{array}{l}\text { Tachypnea, respiratory distress, apnea, tachycardia } \\
\text { and hypotension }\end{array}$ \\
\hline Metabolic & Hypoglycemia, hyperglycemia, or metabolic acidosis \\
\hline Focal infections & $\begin{array}{l}\text { Cellulitis, omphalitis, conjunctivitis, otitis media or } \\
\text { osteomyelitis }\end{array}$ \\
\hline
\end{tabular}

Table 1: Clinical presentations of the septic neonate [2].

The clinician should address the frequency and quality of breastfeeding or how often and how much formula the bottle-fed infants are receiving; frequency of stool and urination is vital. It is really important at assessing the infant that the clinician knows the spectrum activities expected in a healthy neonate. After the first day of life, 8 breast feedings of approximately 15 minutes in each breast or for bottle-fed infants $2 \mathrm{oz}$. feeding over 15 minutes is normal in 8 takes. The average infant produces yellow stools approximately 3 to 6 per day. History of failure to passed meconium in the first $48 \mathrm{hr}$ and about 8 urinations per day are also important to take into account [4].

The clinician should check the weight of the neonate, a normal 10\% of weight loss in the first week is normal, the neonate should return to their normal weight at day 10-14. The newborn gains 20-30 g per day for the first week of life in general. Deviation from these patterns may be indicative if significant disease like cardiac disease o gastrointestinal disorders (Figure 1 and 2).

\section{Physical Examination}

A careful examination helps the physician detect anomalies that may compromise the neonate. The physical examination should begin with an evaluation of neonatal size, weight, and vital signs as heart rate, respiratory rate, oxygen saturation level and temperature. The Pediatric Assessment triangle (PAT) provides an accurate method for rapid assessment of any child or infant with an emergency condition, through visual and auditory evaluation of the infant's appearance, work of breathing and circulation to skin $[5,6]$.

Immediate assessment of airway and breathing is mandatory. Assessing the work of breathing and the respiratory rate with a minute of observation or auscultation is required to accurately assess the respiratory rate and perceive the clinical signs of difficulty in breathing. The presence of congenital heart disease will give multiple clinical findings, as tachypnea, tachycardia, acrocyanosis, poor to absent peripheral pulses and breathing difficulties; and will be address later.

Circulation and hydration can be difficult to assess in neonates. Capillary refill time is helpful and should be less than 2-3 seconds. Hypotension is a late finding of shock; therefore tachycardia must be taken seriously in the ill child.

\begin{tabular}{|c|c|}
\hline Antibiotic & Doses \\
\hline \multirow[t]{6}{*}{ Ampicilin } & $\leq 2000 \mathrm{~g}$ \\
\hline & $0-7$ days: $100 \mathrm{mg} / \mathrm{kg} /$ day $12 \mathrm{~h}$ \\
\hline & $8-28$ days: $150 \mathrm{mg} / \mathrm{kg} /$ day $8 \mathrm{~h}$ \\
\hline & $\geq 2000 \mathrm{~g}$ \\
\hline & $0-7$ days: $150 \mathrm{mg} / \mathrm{kg} /$ day $8 \mathrm{~h}$ \\
\hline & $8-28$ days: $200 \mathrm{mg} / \mathrm{kg} /$ day $6 \mathrm{~h}$ \\
\hline \multirow[t]{9}{*}{ Gentamycin } & $\leq 32$ weeks Gestational Age \\
\hline & $0-14$ days: $15 \mathrm{mg} / \mathrm{kg} /$ day $48 \mathrm{~h}$ \\
\hline & $>14$ days: $15 \mathrm{mg} / \mathrm{kg} /$ day $24 \mathrm{~h}$ \\
\hline & 32-36 weeks Gestational Age \\
\hline & $0-7$ days: $15 \mathrm{mg} / \mathrm{kg} /$ day $24 \mathrm{~h}$ \\
\hline & 7 days: $15 \mathrm{mg} / \mathrm{kg} /$ day $24 \mathrm{~h}$ \\
\hline & $\geq 36$ weeks \\
\hline & $0-7$ days: $15 \mathrm{mg} / \mathrm{kg} /$ day $24 \mathrm{~h}$ \\
\hline & $>7$ days: $17.5 \mathrm{mg} / \mathrm{kg} /$ day $24 \mathrm{~h}$ \\
\hline \multirow[t]{6}{*}{ Cefotaxime } & $\leq 2000 \mathrm{~g}$ \\
\hline & $0-7$ days: $100 \mathrm{mg} / \mathrm{kg} /$ day $12 \mathrm{~h}$ \\
\hline & 8-28 days: $150 \mathrm{mg} / \mathrm{kg} /$ day $8 \mathrm{~h}$ \\
\hline & $\geq 2000 \mathrm{~g}$ \\
\hline & $0-7$ days: $100 \mathrm{mg} / \mathrm{kg} /$ day $12 \mathrm{~h}$ \\
\hline & $8-28$ days: $150 \mathrm{mg} / \mathrm{kg} /$ day $8 \mathrm{~h}$ \\
\hline \multirow[t]{6}{*}{ Vancomycin } & $\begin{array}{l}\text { According to serum creatinine concentrations in a neonate } \\
\geq 28 \text { weeks gestational age }\end{array}$ \\
\hline & $<0.7: 15 \mathrm{mg} / \mathrm{kg} /$ day $12 \mathrm{~h}$ \\
\hline & $0.7-0.9: 20 \mathrm{mg} / \mathrm{kg} /$ day $24 \mathrm{~h}$ \\
\hline & 1-1.2: $15 \mathrm{mg} / \mathrm{kg} /$ day $24 \mathrm{~h}$ \\
\hline & $1.3-1.6: 10 \mathrm{mg} / \mathrm{kg} /$ day $24 \mathrm{~h}$ \\
\hline & $>1.6: 15 \mathrm{mg} / \mathrm{kg} /$ day $48 \mathrm{~h}$ \\
\hline \multirow[t]{6}{*}{ Acyclovir } & $\leq 2000 \mathrm{~g}$ \\
\hline & $0-7$ days: $40 \mathrm{mg} / \mathrm{kg} /$ day $12 \mathrm{~h}$ \\
\hline & $8-28$ days: $60 \mathrm{mg} / \mathrm{kg} /$ day $8 \mathrm{~h}$ \\
\hline & $\geq 2000 \mathrm{~g}$ \\
\hline & $0-7$ days: $60 \mathrm{mg} / \mathrm{kg} /$ day $8 \mathrm{~h}$ \\
\hline & $8-28$ days: $60 \mathrm{mg} / \mathrm{kg} /$ day $8 \mathrm{~h}$ \\
\hline
\end{tabular}

Table 2: Recommended antibiotics and dosages for neonatal sepsis [15].

The normal neonatal heart rate is between 120 and 160 beats per minute, the respiratory rate 40 to 60 breaths per minute and the 
systolic blood pressure 60 to $90 \mathrm{~mm} \mathrm{Hg}$, fever is define as a temperature of $38^{\circ} \mathrm{C}(100.4 \mathrm{~F})$ or above. Abnormalities in respiratory rate, heart rate, or blood pressure can be found in any critically ill neonate $[2,5,7]$.

The complete neurological examination is frequently not possible to perform due to time restraints. A limited neurological examination should include evaluation of the tone, cranial nerves, sensation, strength and primitive reflexes. The physician should know the common primitive reflexes as rooting reflex, walking reflex, tonic neck reflex, Moro reflex, palmar reflex and plantar reflex. Seizures can present with apnea or changes in the tone alone. Seizures may indicate abnormalities including glucose and electrolytes levels, central nervous system infections, and metabolic disease or child abuse [8]. Assessment of the muscular tone is crucial, healthy infants prefer to maintain his arms and legs flexed. Hypotonic can be present in any critical ill infant, while hypertonia should be a concern for seizures or metabolic disease. The cry of the infant should be strong and vigorous. Infants with various neurological problems produce weak or shrill, high-pitched cry [9].

The evaluation of the abdomen includes the same components as with older children. The newborn liver edge frequently is located approximately $1 \mathrm{~cm}$ below the right costal margin and is normal. The spleen should not be palpable and it can become enlarge with certain conditions like hemolyzing states. The umbilical cord should be inspected for signs of infection and bleeding. In the case of constipation or bloody stool, the clinician can perform a rectal examination to assess rectal tone, determine the presence or absence of stool in rectal vault and visualization of bloody stool, as it may be the case of a necrotizing enterocolitis or intussusception.

Assessment of the genitourinary tract is also very important and is usually cover by the diaper. Male infants should be evaluated for hypospadias or other urethral anomalies, inguinal hernias, varicoceles, hydroceles and undescended testis. An incarcerated inguinal hernia can be seen as a hard mass overlying the inguinal canal may be erythematous, and it is usually tender to palpation [10].

The physician should know the benign skin conditions to ensure that pathologic lesions are not hiding among the benign. The most common benign rashes are erythema toxicum occurring in almost 50\% of newborns, it generally appears at trunk within the first $48 \mathrm{~h}$ of life, often progressing to extremities; and is characterized by pinpoint whitish-yellow papules and pustules. In presence of jaundice total and direct bilirubin levels has to be measure, often is associated to breastfeeding or blood breakdown in the setting of an immature liver, but late onset jaundice can also be associated with sepsis or metabolic disease [4].

\section{Approach}

The approach to the critically ill neonate who presents to the ED begins with placement of a cardiac monitor and pulse oximeter; assessment of vital signs; and bedside testing of blood glucose [5]. The temperature of the undressed neonate should be rechecked periodically as young infants have difficulty with regulation due to large body surface. Delivery of oxygen by high flow mask may be sufficient to reverse hypoxia in the ill neonate. If no peripheral intravenous lines can be established, either an intra-osseous line or umbilical catheter must be placed. Blood glucose below $35-40 \mathrm{mg} / \mathrm{dl}$ is consider abnormal in a neonate and should mandate an intervention [11]. If saline boluses are required, the physician should begin with 10 $\mathrm{ml} / \mathrm{kg}$ and then reassessed vital and clinical signs of perfusion. Early communication with the neonatal or pediatric unit will help with the potential transfer of the critically ill neonate.

The presenting features of many serious neonatal disorders are nonspecific. Knowledge of typical and atypical presentation of the different diseases can improve the accuracy of diagnosis of critical illness in neonates.

\section{Laboratory testing}

Ideally, testing should be guided in some degree by clinical suspicion. For many critically ill neonates, however, the underlying diagnosis is unknown because of the unspecific signs and symptoms of the different disease in this population. For any significantly ill neonate, electrolyte, glucose, and calcium levels; a complete blood cell count $(\mathrm{CBC})$; pro-thrombin time (PT); partial thromboplastin time (PTT); and a blood culture should be considered once IV access is obtained. The rest of laboratory tests and their characteristics are considered by diagnosis [2].

\section{Infectious Emergencies}

The presenting symptoms and signs may range from minor complains to shock. One of the main complains is fever, followed by irritability. The physician needs to be cautious with preterm neonates, because they rarely manifest with fever and a high index of suspicion is necessary. Any ill-appearing young infant should be considered septic until proven otherwise [4].

\section{Neonatal Sepsis}

Neonatal sepsis is a cause of high mortality and morbidity even if the antibiotic was administered correctly [12]. It is divided in early onset sepsis (EOS) that is present in the first week of life and late onset sepsis (LOS) from day 7 to 28 days of life. The EOS is associated with vertical transmission and the most common source of infection is the vaginal bacteria flora from the mother [13]. The risk factors have to be address from the perinatal history; the ones that are associated with EOS are prolonged membrane rupture $(>18 \mathrm{~h})$, maternal age $>35$ years, cesarean section, chorioamnionitis, maternal B streptococcal status, maternal fever, the presence of sexually transmitted disease and invasive monitoring. In LOS, its not usually associated with early obstetric complications. These infants may have an identifiable risk factor like central/umbilical catheter and ventilator treatment [13].

In EOS, Group B streptococcus, and E. coli are the most common bacteria causing neonatal sepsis [13]. Other bacterial microorganism causing infections are Lysteria monocytogened, klebsiella, enterococcus, non-group $\mathrm{D}$ a-hemolytic streptococcus, and $H$. influenza. Overall viral microorganisms are the most common cause of infection. They include infections by herpes simplex, enteroviruses and adenovirus [4]. In LOS, Gram-positive bacteria are the most common cause of infection like CoNS, S.aureus and Enteroccoccus sp.

Clinical signs of sepsis may be subtle. Lethargy, irritability, and decreased oral intake are common. Other clinical features include vomiting, diarrhea, temperature instability (high or low), abdominal distention or ileus, apnea, tachypnea, cyanosis, pallor, petechial and poor perfusion [4]. The physical examination should look for the sources of infection such as omphalitis; that is a localized infection of the umbilical cord stump, most commonly caused by a single organism, which usually responds well to appropriate antibiotics [14]. 


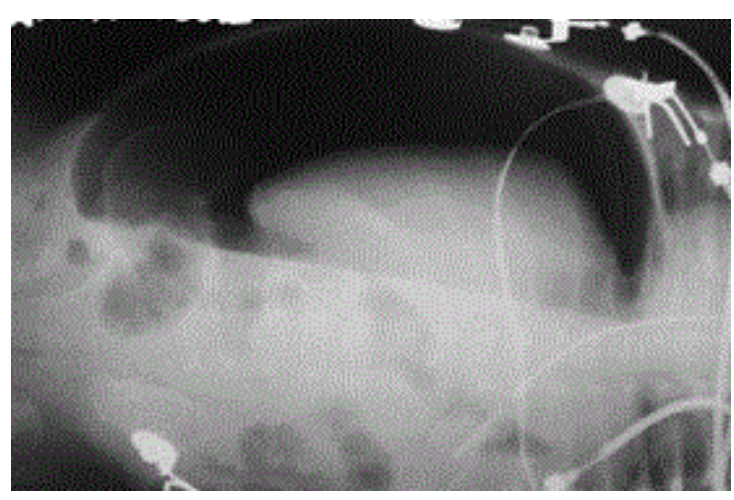

Figure 3: Patient with free air in the abdomen secondary to a perforated segment of the abdomen in a lateral abdominal radiograph.

Standard laboratory tests for the neonate with suspected sepsis should include complete blood count with differential (CBC); urinalysis; cerebrospinal fluid (CSF); blood, urine and CSF culture; Creaction protein (CRP), calcium level; electrolyte and PT/PTT, chest radiograph. Urine should be collected by bladder catheterization or supra-pubic aspiration because bag urine specimens are associated with high rates of contamination. Chest radiographs are indicated only in the presence of respiratory of respiratory symptoms and stool analysis only if the patient has diarrhea [2].

The CBC is usually ordered for the evaluation of sepsis. An immature-neutrophil to total neutrophil ratio greater than 0.2 is 60 to $90 \%$ sensitive and $70 \%-80 \%$ specific for diagnosing neonatal sepsis.

The CRP is a non-specific marker of inflammation, and its elevation is not limited to sepsis. The main limitation is that it needs $8-10 \mathrm{~h}$ for synthesis, giving a great variability in the sensitivity in predicting sepsis [2]. There are more studies in regards to serum markers (necrosis factor-alpha (TNF-a), Interleukin-6 (IL-6) and IL-8)) as diagnostic tools to detect sepsis and its severity. According to the literature, they can help in differentiating bacterial from viral and fungal microorganism. These indicators can be detected in blood early but their short half-life, limits their use in clinical practice. Other diagnostic study that has been used is the procalcitonin with good specificity [13].

All septic infants should be admitted to the hospital. Management includes correction of hypovolemia, electrolyte abnormalities, hypothermia and antibiotics should administer in the ED. The emergency physician should commence ampicillin and gentamycin as empiric therapy; and depending on the antibiotic resistance a third generation cephalosporin might be necessary to add to the treatment. In LOS, vancomycin plus an aminoglycoside is recommended. Ceftriaxone is not recommended for neonates who are jaundiced because of the concern of inducing unconjugated hyperbilirubinemia $[15,16]$.

\section{Neonatal herpes (HSV)}

Neonatal herpes is an uncommon infection occurring in 1 of every 32000 deliveries. Neonates with central nervous system (CNS) HSV infection usually present during the second and third weeks of life. The most common risk factor is birth to an HSV infected mother. This risk is highest with vaginal delivery in mothers with primary genital infection. Other risk factors include: duration of ruptures membranes, integrity of cutaneous barriers, maternal antibody status, mode of delivery, type of HSV (HSV 1 vs 2). The infection can be acquired in utero, peri-partum or post natal [17].

There are 3 clinical classifications of neonatal HSV infection that are predictive of morbidity and mortality: disseminated, CNS, and skin, eye, or mouth diseases [18]. Disseminated disease accounts for $25 \%$ of HSV infections and involves multiple organs including the liver, lung, adrenal glands, skin, eye, and brain. CNS involvement occurs in about $60 \%$ to $75 \%$ of patients with disseminated disease. CNS disease without disseminated disease accounts for $30 \%$ of HSV infections and may or may not have skin, eye, or mouth involvement. Skin, eye, or mouth disease accounts for approximately $45 \%$ of HSV disease; involves only skin, eye, and/or mouth; and does not include CNS or disseminated HSV infection [19].

The clinical presentation of HSV infection in the neonate depends on the type and duration of disease. The symptoms may be subtle. Vesicular lesions are the most specific finding for HSV infection but are present in less than half. Other clinical features of neonatal HSV include temperature instability, irritability, lethargy, seizures, and respiratory distress. A high index of suspicion is important because early detection and treatment with acyclovir, has been shown to decrease the mortality from $90 \%$ to $31 \%$. A chest radiograph may demonstrate pneumonitis.

The American Academy of Paediatric Committee on Infectious Diseases recommends HSV cultures and PCR and whole blood sample for measuring alanine aminotransferase in the diagnostic evaluation of any neonate with suspected HSV infection. Detection of HSV antigen by direct immunofluorescence assay and histologic examination for multinucleated giant cells and intranuclear inclusions by Tzanck test are not sensitive for HSV infection and should be avoided. Definitive laboratory diagnosis may be provided by the isolation of HSV through culture. HSV PCR is more sensitive than viral culture for the detection of HSV in the CSF and blood, and is the preferred test for the detection of CNS and disseminated disease [20].

Treatment should be considered in any patient with fever, irritability, abnormal CSF findings, and especially seizures. Management should include supportive care, broad-spectrum antibiotics for sepsis, and administration of acyclovir (Table 1 and 2) [15]. Parenteral acyclovir is recommended for the treatment of neonatal HSV infection. The duration of the treatment will depend on the classification of HSV infection.

\section{Cardiac Emergencies}

The incidence of congenital heart disease (CHD) requiring specialized cardiac care is estimated to be $500-600$ per 100,000 live births. The most critical presentations in the infant with cardiac disease include cyanotic episodes, congestive heart failure (CHF), cardiogenic shock or cardiovascular collapse and arrhythmias [21]. Cardiac disease in the infant can be the result of structural aberrations, conduction abnormalities and acquired illnesses.

Congenital heart disease can be divided in three main categories: left-sided obstructive lesions, right-sided obstructive lesions, and mixed lesions with increased pulmonary blood flow. The main lesions that will present in the neonatal period are in the left-sided obstructive lesions include coarctation of the aorta, hypoplastic left-heart 
syndrome, interrupted aortic arch, aortic atresia, and mitral valve atresia. Right-sided obstructive lesions include tetralogy of Fallot (TOF) hypoplastic right-heart syndrome, pulmonary valve atresia, pulmonary valve stenosis, Ebstein's anomaly, and tricuspid valve atresia. Mixed lesions with increased pulmonary vascular flow include total anomalous pulmonary venous return, transposition of the great vessels, and truncus arteriosus [4]. Also, depending on where the flow obstruction is it could be categorized in cyanotic and acyanotic.

\begin{tabular}{|c|c|}
\hline Congenital Heart Disease & \\
\hline Acyanotic Heart Disease (Infants with acyanotic heart & Aortic stenosis \\
\hline & $\begin{array}{l}\text { Arteriovenous } \\
\text { malformation }\end{array}$ \\
\hline & Coartation of Aorta \\
\hline & $\begin{array}{l}\text { Complete } \\
\text { Arterivenous canal }\end{array}$ \\
\hline & $\begin{array}{l}\text { Endocardial Cushing } \\
\text { defect }\end{array}$ \\
\hline & Hypoplastic left heart \\
\hline & Interrupted Aortic Arch \\
\hline & $\begin{array}{l}\text { Patent } \quad \text { ductus } \\
\text { arteriosus }\end{array}$ \\
\hline & $\begin{array}{l}\text { Ventricular Septal } \\
\text { Defect }\end{array}$ \\
\hline $\begin{array}{l}\text { Cyanotic Heart Disease } \\
\text { (Infants with cyanotic heart disease are usually unable }\end{array}$ & $\begin{array}{l}\text { Transposition of the } \\
\text { great vessels }\end{array}$ \\
\hline to achieve $\mathrm{PaO}_{2}$ of $>100 \%$ after hyperoxia test) & $\begin{array}{lr}\text { Total anomalous } \\
\text { pulmonary } \\
\text { return }\end{array}$ \\
\hline & Tetralogy of Fallot \\
\hline & Truncus arteriosus \\
\hline & Tricuspid Atresia \\
\hline & $\begin{array}{l}\text { Severe } \\
\text { stenosis }\end{array}$ \\
\hline
\end{tabular}

*Hyperoxia test: breathing $100 \%$ oxygen for $10-20$ minutes

Table 3: Types of Congenital Heart Disease.

The timing of presentation of CHD is bimodal, such that ductaldependent defects primarily present in the first weeks of life and leftto-right shunting lesions present between 1 and 6 months of age. The diagnostic dilemma of the newborn with congenital heart disease must be resolve in a time manner because therapy may probe to be life saving for some of these infants (Table 3). Routine screening to find neonates with $\mathrm{CHD}$ should be perform at the nurseries. A pulse oxymetry at room in the lower extremities (postductal saturation) may of great value. A pulse oxymetry above $96 \%$ rules out a completely ductal-dependent left heart obstruction (hypoplastic left heart or interrupted aortic arch) [22].

Perinatal history can give physicians clues of a possible newborn with a heart disease, certain substance consumption, exposure, maternal factors and infections are associated with heart abnormalities.
The diagnosis of CHD should be considered in any previously healthy infant presenting with respiratory distress and/or shock. There are 2 types of ductal-dependent defects. Obstructive lesions of the right side of the heart (e.g., tricuspid atresia, pulmonary atresia) require an open DA to provide adequate pulmonary blood flow. Obstructive lesions of the left side of the heart (e.g., hypoplastic left ventricle, coarctation of the aorta) require the DA to maintain adequate systemic blood flow. As the DA begins to close, obstructive right heart lesions will develop cyanosis and obstructive left heart lesions will develop hypoperfusion, shock, and pulmonary edema.

The clinical presentation of infants presenting to an ED with a congenital heart disease have one of this four presentations: 1) asymptomatic murmur, 2) cyanosis (often without a murmur), 3) gradually progressing symptoms of heart failure, or 4) catastrophic heart failure and shock. The latter two presentations almost always occur in the first week of life. Critical clues in an infant that should lead to the consideration of a cardiac diagnosis rather than sepsis include the presence of a gallop rhythm and marked hepatomegaly or cardiomegaly. Profound metabolic acidosis with $\mathrm{pH}$ values of 7.0 or less is characteristic. The age and time of presentation in addition to the severity of presenting symptoms in an infant with underlying CHD will vary depending upon the specific defect, the complexity and severity of the defect, and the timing of normal physiologic changes that occur as the fetal circulation transitions to that of the neonate. In general, the more severe defects with compromised pulmonary or systemic blood flow tend to present earlier during infancy, while less severe defects may not become clinically apparent until early childhood [21].

\section{Evaluation of a neonate with suspected CHD}

Laboratory tests are less useful in the diagnosis of congenital heart disease. A hemoglobin and hematocrit level may reveal a compensatory physiologic elevation in infants with a cyanotic CHD. A CBC may be helpful in determining the need for a transfusion in patients with cyanotic congenital heart disease and biochemistry may guide electrolyte replacement or the correction of acidosis. In patients with poor systemic perfusion, such as those with hypoplastic left heart syndrome, acidosis can be profound and may be a clue to diagnosis.

The chest radiograph often offers clues and is very helpful if abnormal. Three important radiographic features requiring assessment are: the cardiac size, the shape of the cardiac silhouette, and the degree of the pulmonary vascular markings. The cardiac width to thoracic ratio is not as reliable in young infants. The AP view is affected by inspiration and the thymus. On radiograph, some neonates with congenital heart disease have the characteristic appearance of a boot (tetralogy of Fallot), an egg on a string (TGA or TAPVR), or a snowman (total anomalous pulmonary venous return) [2].

An ECG is another useful diagnostic tool in the evaluation of an infant with a suspected underlying CHD. The problem is that around $54 \%$ of the patients with a CHD could have a normal ECG [23].

The echocardiogram is the study of choice for the final diagnosis of a congenital heart disease in the ED, specially if perform by a pediatric cardiologist [2]. However, bedside echocardiography is not available in many EDs, and clinicians must rely upon clinical examination, ECG, chest radiograph and limited bedside test (eg. arterial blood gases) to initiate treatment in patients with suspected CHD. 


\section{Management}

Treatment depends on whether the patient is stable. In any critically ill neonate the priority should be the assessment of the airway, breathing and circulation. The airway management should be the first major intervention after the initial assessment [6]. Stabilization of the airway and mechanical ventilation can prevent respiratory decompensation. The specific treatment of CHD in any given case will depend upon whether there is a volume overload (left-to-right shunts), excess afterload (left heart obstructive lesions), rhythm abnormalities, or decreased contractibility (e.g. cardiomyopathy).

The administration of supplemental oxygen for patients with cyanosis and administration of agents to increased cardiac contractibility and improve the cardiac output are necessary in the majority of the patients that presents to an ED. Fluid resuscitation as well as respiratory and inotropic support is essential treatments for these very sick infants, although systemic blood flow and reversal of shock cannot be achieved until ductus arteriosus patency is reestablished with prostaglandin E1 IV infusion. The initial dose is $0.05-1 \mu \mathrm{g} / \mathrm{kg} / \mathrm{min}$. Improvement usually is seen within 15 minutes. Some of the complications seen with prostaglandin is apneas, so the physician should be ready for the management of a definite airway [4]. If the clinical suspicion of critical coarctation or hypoplastic left heart syndrome is high, prostaglandin infusion should be started prior to echocardiographic confirmation of the diagnosis. Some of the patients with congenital heart lesions will ultimately require surgical intervention. Because sepsis cannot rule out in these patients it is recommend doing a full sepsis work up and starting the administration of antibiotics [21].

\section{Neurological emergencies}

Recognizing a neurologic insult may be difficult, because clinical symptoms can be unspecific and subtle. The only behaviour change may be as subtle as changes in the feeding pattern.

\section{Seizures}

Neonatal seizures are poorly classified, under-recognized, and often difficult to treat. The presence of neonatal seizures often signals an underlying ominous neurological condition, most commonly perinatal hypoxia-ischemia. Recognizing seizures in the neonatal group are often difficult, generalized motor activity is less common, since cortical development is not complete. Many neonatal seizures involve subtle motor automatisms (abnormal eye movements (usually horizontal, sustained eye deviation), abnormal tongues movements, pedalling) and the generalized tonic-clonic seizures are rarely seen because of central nervous system immaturity. Mortality ranges from $15-40 \%$.

The most common etiology of neonatal seizures is hypoxic-ischemic encephalopathy, the seizures usually begin within the first $24 \mathrm{~h}$ after birth. Hypoxic-ischemic encephalopathy probably accounts for approximately $50 \%$ to $60 \%$ [24].

Lethargy, vomiting, temperature instability, or subtle changes in physiologic homeostasis usually identify sepsis. Any infant with these symptoms should have a septic work-up, including blood, urine, and cerebrospinal fluid (CSF) cultures. Intracranial infections probably account for $5 \%$ to $10 \%$ of all causes for neonatal seizures. The most common etiologies for nonbacterial infections include toxoplasmosis, cytomegalovirus, and herpes simplex. Bacterial infections include group B streptococcus, Listeria, and Escherichia coli. These infections usually are seen towards the end of the first week of life or even later than the congenital viral infections and up to three months [25].

Intracranial hemorrhage accounts for approximately $10 \%$ of all cases. The germinal matrix-intraventicular hemorrhages are the cause of the majority of these seizures. In general, these hemorrhages present clinically with lethargy and a sudden drop in hematocrit, usually within the first 3 days of life. Generalized tonic seizures are the most typical seizures, although subtle seizures have also been observed [25].

\begin{tabular}{|c|c|c|}
\hline First day of life & Second day of life & $\begin{array}{l}\text { Day } 4 \text { to } 6 \text { months of } \\
\text { age }\end{array}$ \\
\hline Anoxia/hypoxia & $\begin{array}{l}\text { Benign familial neonatal } \\
\text { seizures }\end{array}$ & $\begin{array}{l}\text { Benign idiopathic } \\
\text { neonatal seizures }\end{array}$ \\
\hline Drugs & $\begin{array}{l}\text { Congenital anomalies or } \\
\text { development } \\
\text { disorders }\end{array}$ & $\begin{array}{l}\text { Congenital anomalies } \\
\text { or development brain } \\
\text { disorders }\end{array}$ \\
\hline $\begin{array}{l}\text { Hypoglycemia/ } \\
\text { hyperglycemia }\end{array}$ & Drug withdraw & Drug withdraw \\
\hline Infection & Hyperphosphatemia & Hyperphosphatemia \\
\hline Intracranial hemorrhage & Hypertension & Hypertension \\
\hline Pyridoxine deficiency & Hypocalcemia & Hypocalcemia \\
\hline \multirow[t]{5}{*}{ Trauma } & Hypoglycemia & Hypoglycemia \\
\hline & $\begin{array}{l}\text { Hyponatremia/ } \\
\text { hypernatremia }\end{array}$ & $\begin{array}{l}\text { Hyponatremia/ } \\
\text { hypernatremia }\end{array}$ \\
\hline & $\begin{array}{l}\text { Inborn errors of } \\
\text { metabolism }\end{array}$ & $\begin{array}{l}\text { Inborn errors of } \\
\text { metabolism }\end{array}$ \\
\hline & Sepsis & Sepsis \\
\hline & Trauma & \\
\hline
\end{tabular}

Table 4: Causes of Neonatal seizures $[3,4]$.

Metabolic disturbances can also cause neonatal seizures. Electrolyte disturbances are the most common etiology and include hypoglycemia, hypocalcemia, and hypomagnesemia [26]. Hypernatremia and hyponatremia can also produce seizures in the neonatal period but are less common. Inborn errors of metabolism are rare causes of seizures in the neonatal population. Pyridoxine dependency, a defect in pyridoxine metabolism, is a rare disorder, but produces severe seizures in the neonatal period that are resistant to antiepileptic drug therapy. Table 4 shows a list of causes of neonatal seizure according to age of the infant.

Emergency evaluation should include prenatal and perinatal history. Important information to determine the possible cause are infection risks, prenatal infection (STORCH: syphilis, toxoplasmosis, other infections, rubella, cytomegalovirus and herpes simplex) studies, substance abuse, perinatal asphyxia, or family history of seizures. The physical examination should include blood pressure; look for unusual odor of sweat or urine, because this can indicate inborn errors of metabolism, the skin (evaluate for jaundice, café-au-lait spots, or herpes vesicles) and a complete neurological exam.

The initial management is stabilizing the airway, breathing and circulation, supplementation of oxygen and obtaining a bedside blood glucose levels. Laboratory tests should include glucose, sodium, calcium and magnesium levels. Other tests to consider include 
Page 7 of 9

hematocrit, electrolytes, blood urea and nitrogen, phosphate, serum ammonia, blood gases and possibly blood cultures and lumbar puncture [4]. The most important part of the evaluation and management is establishing the etiology of the seizures.

For patients actively seizing the initial drug of choice are benzodiazepines in this case Lorazepam is the preferred drug for neonatal seizures. If the seizure does not stop with the first line treatment Phenobarbital should be the second line agent, followed by fosphenytoin or phenytoin. In some patients with refractory status epilepticus after the second line therapy they will need airway management and the administration of an infusion of midazolam with intensive care unit admission [27]. If a low blood glucose $(\leq 40$ $\mathrm{mg} / \mathrm{dL}$ ) is detected it should be corrected immediately with a bolus of $10 \%$ dextrose of 2-4 ml/kg [11]. Pyridoxine (Vitamine B6) $100 \mathrm{mg}$ can be administered if seizing persist after standard anticonvulsant therapy and verification of normal glucose. Acyclovir can be added if there is suspicion of encephalitis (Table 2) [3].

After seizures stopped; cranial computed tomography (CT) is required if an obvious cause is not found on initial evaluation or cranial ultrasound can be perform to identify hemorrhage. Patients with seizures often require continuous video EEG monitoring [25].

\begin{tabular}{|l|l|}
\hline Drug & Dosage \\
\hline Benzodiazepines & \\
\hline$\cdot$ Lorazepam & $0.05-0.1 \mathrm{mg} / \mathrm{kg} \mathrm{IV}$ \\
\hline$\cdot$ Diazepam & $0.2-0.3 \mathrm{mg} / \mathrm{kg} \mathrm{IV} \mathrm{or} 0.5 \mathrm{mg} / \mathrm{kg}$ rectal \\
\hline$\cdot$ Midazolam & $0.1 \mathrm{mg} / \mathrm{kg}$ IV \\
\hline & Infusion $1-18 \mathrm{mcg} / \mathrm{kg} / \mathrm{min}$ \\
\hline Phenobarbital & $\begin{array}{l}20 \mathrm{mg} / \mathrm{kg} / \mathrm{IV} \text { initially then repeat } 10 \mathrm{mg} / \mathrm{kg} \mathrm{IV} \mathrm{q} 10 \mathrm{~min} \\
(\mathrm{maximum} \text { of } 50-60 \mathrm{mg} / \mathrm{kg})\end{array}$ \\
\hline Phenytoin & $15-20 \mathrm{mg} / \mathrm{kg}$ IV \\
\hline
\end{tabular}

Table 5: Pharmaceutical management of neonatal seizures [3].

\section{Endocrine emergencies}

\section{Hyperbilirubinemia}

Hyperbilirubinemia with jaundice is an important clinical feature in certain neonates with serious illness. Jaundice in the newborn is a unique problem because elevation of the serum bilirubin is potentially toxic to the infants developing central nervous system; especially in neonates who are premature, or those with hypoxia, hypercabnia, and acidosis. The levels of concern will be directed by the age of presentation, associated symptoms and the type of bilirubin that is elevated (unconjugated or conjugated).

The diagnosis of unconjugated hyperbilirubinemia can range from normal physiologic processes to rare, life-threatening disorders. The most common cause of unconjugated hyperbillirubinemia is the physiologic type. Table 5 shows common causes of unconjugated hyperbilirubinemia. Pathologic causes of elevated unconjugated bilirubin exist, including $\mathrm{ABO}$ incompatibility, inherited red cell disorders, hematomas, and bowel obstruction [28].

The initial step with the jaundiced neonate begins with a thorough history and physical examination. There are common risk factors for severe hyperbilirubinemia. The initial evaluation should include total and direct bilirubin, hematocrit level, reticulocyte count and Coombs test. Risk factors for more severe illness are prematurity, jaundice within the first $24 \mathrm{~h}$ of life, rapid rate of increase of bilirubin $(>0.5$ $\mathrm{mg} / \mathrm{dL} / \mathrm{h}$ ), anemia, and the presence of hepatosplenomegaly [28].

\begin{tabular}{|l|}
\hline Physiologic Hyperbilirubinemia (most common) \\
\hline Breastfeeding and breastmilk jaundice \\
\hline Increased production of bilirubin: \\
- Sequestered blood (cephalohematoma, subdural hematoma, ecchymosis, \\
- Sepsis \\
- Hemolysis ( immune and noninmune) \\
\hline Decreased hepatic uptake or conjugation: \\
- Congenital hypothyroidism \\
- Gilbert syndrome \\
- Crigler- Najjar syndrome (Type I and II) \\
- Lucey- Driscoll syndrome \\
- Down syndrome
\end{tabular}

Table 6: Causes of unconjugated Hyperbilirubinemia [28].

\begin{tabular}{|l|}
\hline Major Risk factors \\
\hline - Jaundiced observed in the first $24 \mathrm{~h}$ \\
- Blood group incompatibility with positive antiglobulin test, other known \\
- Gestational aged 35 to 36 weeks \\
- Previous sibling received phototherapy \\
- Cephalohematoma or significantly bruising \\
- Exclusive breastfeeding, particularly if nursing is not going well and excessive \\
weight loss \\
\hline Minor Risks factors \\
\hline - Gestational aged 37 to 38 weeks \\
$\cdot$ Jaundiced observed before discharge \\
- Previous sibling had jaundice \\
- Macrosomia in an infant of a diabetic mother \\
- Maternal age $>25$ years \\
- Male sex \\
\hline Decreased risk \\
\hline - Gestational aged $>41$ weeks \\
- Exclusive formula feeding
\end{tabular}

Table 7: Risks Factor of Severe Hyperbilirubinemia in infants $>35$ weeks [29].

For patients with unconjugated hyperbilirubinemia, phototherapy is the mainstay treatment. If the patient is critically ill a sepsis work up is necessary and the priority should be the management of airway, breathing and circulation. Some of them could need exchange transfusion or intensive phototherapy depending on the level of bilirubin and presence of risk factors [29]. 
Page 8 of 9

Elevated conjugated bilirubin, defined as greater than $2 \mathrm{mg} / \mathrm{dl}$ or greater than $20 \%$ of the total bilirubin, is always abnormal [28]. The work-up is directed at identifying and treating underlying disorder. Table 6 shows the different causes of conjugated hyperbilirubinemia. The laboratory tests are crucial to determinate the causes, like TORCH serology's, blood gas, lactate, complete liver function panel, ammonia, electrolytes, blood urea nitrogen and creatinine. In special situations it can included reducing substances, alpha1- antitrypsin, sweat chloride, abdominal imaging and others test as needed (Table 7).

\section{Gastrointestinal emergencies}

Vomiting (bilious and non-bilious), diarrhea, gastrointestinal bleeding, and jaundice are important clinical features that may indicate critical illness in neonates. It is important to differentiate between bilious and non-bilious vomiting. In a neonate, bilious vomiting is a surgical emergency until proven otherwise.

\section{Volvulus}

Volvulus begins with the congenital malrotation of the midgut portion of the intestine. During the embryonic life, the intestine rotates 270 degrees and if there is no rotation or incomplete rotation there will be an anomaly in the mesenteric attachment and fixation of the midgut will not develop [30].

\begin{tabular}{|c|c|}
\hline Hepatobiliary disorders & Sepsis \\
\hline & $\begin{array}{l}\text { TORCH (Toxoplasmosis, echovirus, syphilis, } \\
\text { varicella, parvovirus B19, rubella, cytomegalovirus, } \\
\text { herpes) }\end{array}$ \\
\hline & Prolonged parental nutrition \\
\hline & Severe hemolytic disease \\
\hline & $\begin{array}{l}\text { Metabolic disorders (galactosemia, glycogen storage } \\
\text { diseases) }\end{array}$ \\
\hline \multirow{6}{*}{$\begin{array}{l}\text { Ductal disturbances in } \\
\text { biliary excretion }\end{array}$} & Biliary atresia \\
\hline & Choledochal cyst \\
\hline & Bile plug syndrome \\
\hline & Cistyc fibrocis \\
\hline & Alpha1- antitrypsin deficiency \\
\hline & Hepatic infarction \\
\hline
\end{tabular}

Table 8: Causes of Conjugated Hyperbilirubinemia.

The clinical manifestation of malrotation in infant varies with the child's are and level of obstruction. Infants younger than 2 months of age usually present with bilious vomiting and some abdominal distention. In general, the younger the infant at the time of presentation, the more severe the obstruction and the lower the likelihood that the infant will be able to tolerate feeds. Other symptoms include, loss of appetite, apneas, constipation and poor growth. Volvulus usually causes complete obstruction with disruption of the blood supply to the intestine. Infants with complete obstruction and ischemia will become ill quickly and may present with shock (Table 8).

A complete blood cell count, electrolytes, blood urea, nitrogen, creatinine and type and crossmatch are usually obtained in these patients and may reveal dehydration, acidosis, or and elevated white blood cell count. However, these tests are not useful in diagnosing malrotation or midgut volvulus. Plain abdominal radiographs are often non-diagnostic. When results are abnormal, classic findings of malrotation with volvulus include a distended bubble of air in the stomach and proximal duodenum with an otherwise gasless abdomen. Occasionally, free air from a perforated segment of ischemic bowel may be appreciated [30] (Figure 3).

The diagnostic test of choice is an upper gastrointestinal (UGI) study, which has a sensitivity of $96 \%$ for malrotation. The bird-beak sign (contrast in the dilated proximal duodenum) and the appearance of contrast in a spiral or corkscrew pattern in the duodenum are considered positive signs for malrotation. Few studies have examined use of ultrasound in diagnosis of malrotation, but it is likely to have efficacy as a screening tool in equivocal cases.

The primary goal of the initial treatment in all cases is a careful assessment of fluid and electrolyte status with appropriate replacement. For malrotation with or without volvulus, the hallmark of treatment in neonates is surgery. The infant needs to be stabilized medically while awaiting surgical correction. Surgery may consist of a single stage, or it may require a second look to determine if the bowel is viable. In the $\mathrm{ED}$, infants should have a nasogastric tube placed and should receive fluid resuscitation with correction of electrolyte levels. Antibiotics effective against enteric organisms should be administered if shock or peritonitis is present [31].

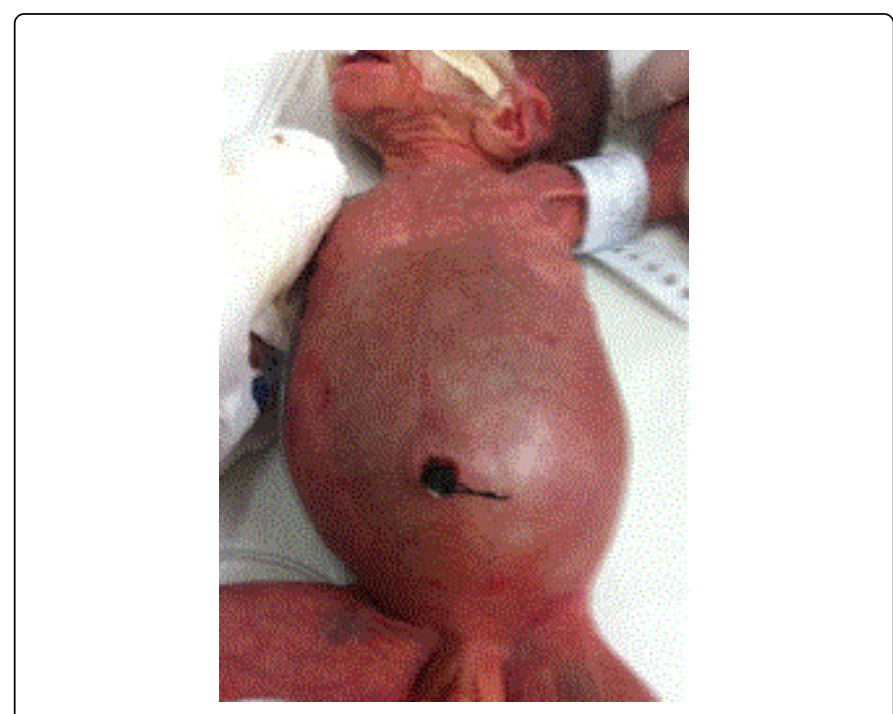

Figure 4: A 5 day preterm infant presented to the emergency department with distended abdomen, irritability and bloody stools.

\section{Necrotizing Enterocolitis}

Necrotizing enterocolitis (NEC) is usually seen in premature infants but can be seen in term infants, usually in the first 10 days of life. Often these infants have a history of an anoxic event or stress at birth. Infants with NEC can appear ill, with lethargy, irritability, anorexia, a distended abdomen, and bloody stools. Mortality is high (between $20 \%$ and $40 \%$ ) [32].

The etiology of NEC is not known, but it is suspected to be multifactorial. Ischemia and reperfusion insults to the bowel are implicated and, although infection may be a factor, no particular agent 
has been identified. Laboratory data can be helpful in making the diagnosis of NEC and helping direct the medical therapy. A complete blood cell count can show leukocytosis and anemia, as well as thrombocytopenia, which are a hallmark of NEC; a blood culture should be obtained prior to starting antibiotics. Serum electrolytes can show hyponatremia, which is poor prognostic indicator of capillary fluid leakage in the bowel, as well as signs of acidosis [32].

For NEC, plain radiograph is the current diagnostic standard, and signs include intraluminal gas, portal venous gas, free intra-peritoneal gas, and dilated loops of bowel, bowel wall thickening, and perforation. Perforation occurs in $12 \%$ to $31 \%$ of cases. Significant radiologic evidence is seen in $90 \%$ of ill neonates with NEC, with bowel dilatation being the most common and sensitive sign [2]. Ultrasonography has the potential advantage of also identifying intra-abdominal fluid and assessing perfusion and thickness of the bowel wall. It may be more sensitive than plain radiograph in the detection of intramural and portal venous gas.

Treatment of NEC includes placement of an orogastric or nasogastric tube, initiation of antibiotics with anaerobic and gramnegative coverage (ampicilin, gentamycin, metronidazole), and aggressive hydration. Pneumoperitoneum is considered a criterion for surgical intervention. For patients without pneumoperitoneum, repeated radiographs are recommended every 6 to $8 \mathrm{~h}$ to assess for progression of NEC [2] (Figure 4).

\section{Conclusion}

Very different types of illnesses can affect an infant in the neonatal period. It is the responsibility of the emergency physician to assess the patient and to treat the unstable neonate, narrow the differential diagnosis to the most likely and begin life-sustaining treatment. Laboratory tests and ancillary studies can be helpful, but empiric treatments must often be started on the basis of suspicion, rather than a definitive diagnosis.

\section{References}

1. Calado CS, Pereira AG, Santos VN, Castro MJ, Maio JF (2009) What brings newborns to the emergency department?: a 1-year study. Pediatr Emerg Care 25: 244-248.

2. Claudius I (2010) An Evidence-Based Review of Neonatal Emergencies. Pediatr Emerg Med Pract 7: 8-9.

3. Brousseau T, Sharieff GQ (2006) Newborn emergencies: the first 30 days of life. Pediatr Clin North Am 53: 69-84, vi.

4. McCollough M, Sharieff GQ (2002) Common complaints in the first 30 days of life. Emerg Med Clin North Am 20: 27-48, v.

5. Giesinger RE, McNamara PJ2 (2016) Hemodynamic instability in the critically ill neonate: An approach to cardiovascular support based on disease pathophysiology. Semin Perinatol .

6. Corrales AY, Starr M (2010) Assessment of the unwell child. Aust Fam Physician 39: 270-275.

7. Rosenstock EG, Cassuto Y, Zmora E (1999) Heart rate variability in the neonate and infant: analytical methods, physiological and clinical observations. Acta Paediatr 88: 477-482.

8. Pisani F, Spagnoli C1 (2016) Neonatal Seizures: A Review of Outcomes and Outcome Predictors. Neuropediatrics 47: 12-19.
9. Mercuri E, Ricci D, Pane M, Baranello G (2005) The neurological examination of the newborn baby. Early Hum Dev 81: 947-956.

10. Lewis ML (2014) A comprehensive newborn exam: part II. Skin, trunk, extremities, neurologic. Am Fam Physician 90: 297-302.

11. Adamkin DH (2016) Neonatal hypoglycemia. Curr Opin Pediatr .

12. Wynn JL, Wong HR, Shanley TP, Bizzarro MJ, Saiman L, et al. (2014) Time for a neonatal-specific consensus definition for sepsis. Pediatr Crit Care Med 15: 523-528.

13. Cortese F, Scicchitano P, Gesualdo M, Filaninno A, De Giorgi E, et al. (2015) Early and Late Infections in Newborns: Where Do We Stand? A Review. Pediatr Neonatol .

14. Fraser N, Davies BW, Cusack J (2006) Neonatal omphalitis: a review of its serious complications. Acta Paediatr 95: 519-522.

15. John S. Bradley (2014) Nelson's Pediatric Antimicrobial Therapy. (20th edn), American Academy of Pediatrics, United States.

16. Obiero CW, Seale AC, Berkley JA (2015) Empiric treatment of neonatal sepsis in developing countries. Pediatr Infect Dis J 34: 659-661.

17. Pinninti SG, Kimberlin DW (2013) Maternal and neonatal herpes simplex virus infections. Am J Perinatol 30: 113-119.

18. Enright AM, Prober CG (2002) Neonatal herpes infection: diagnosis, treatment and prevention. Semin Neonatol 7: 283-291.

19. Whitley RJ, Corey L, Arvin A, Lakeman FD, Sumaya CV, et al. (1988) Changing presentation of herpes simplex virus infection in neonates. J Infect Dis 158: 109-116.

20. Caviness AC, Demmler GJ, Selwyn BJ (2008) Clinical and laboratory features of neonatal herpes simplex virus infection: a case-control study. Pediatr Infect Dis J 27: 425-430.

21. Silberbach M, Hannon D (2007) Presentation of congenital heart disease in the neonate and young infant. Pediatr Rev 28: 123-131.

22. Goetz EM, Magnuson KM, Eickhoff JC, Porte MA, Hokanson JS (2016) Pulse oximetry screening for critical congenital heart disease in the neonatal intensive care unit. J Perinatol 36: 52-56.

23. Narchi H (1999) Neonatal ECG screening for congenital heart disease in Down syndrome. Ann Trop Paediatr 19: 51-54.

24. Stafstrom CE (1995) Neonatal seizures. Pediatr Rev 16: 248-255.

25. Zupanc ML (2004) Neonatal seizures. Pediatr Clin North Am 51: 961-978, ix.

26. Cockburn F, Brown JK, Belton NR, Forfar JO (1973) Neonatal convulsions associated with primary disturbance of calcium, phosphorus, and magnesium metabolism. Arch Dis Child 48: 99-108.

27. Maytal J, Novak GP, King KC (1991) Lorazepam in the treatment of refractory neonatal seizures. J Child Neurol 6: 319-323.

28. Park E, Pearson NM, Pillow MT, Toledo A (2014) Neonatal endocrine emergencies: a primer for the emergency physician. Emerg Med Clin North Am 32: 421-435.

29. American Academy of Pediatrics Subcommittee on Hyperbilirubinemia (2004) Management of hyperbilirubinemia in the newborn infant 35 or more weeks of gestation. Pediatrics 114: 297-316.

30. Ratnayake K, Kim TY (2014) Evidence-based management of neonatal vomiting in the emergency department. Pediatr Emerg Med Pract 11: $1-20$.

31. Liu LM, Pang LM (2001) Neonatal surgical emergencies. Anesthesiol Clin North America 19: 265-286.

32. Lim JC, Golden JM, Ford HR (2015) Pathogenesis of neonatal necrotizing enterocolitis. Pediatr Surg Int 31: 509-518. 